\title{
The Logic of the Copy, from Appropriation to Choreography
}

\section{Claudia Kappenberg}

$\mathrm{n}$ film, video, and fine art practices the appropriation of an existing public repertoire of
images, broadcast media and archives of all kinds is a well-established strategy for a critical
engagement with the everyday. By comparison, work that is made under the umbrella of screendance tends to be composed with new movement material. Both Appropriation Art and screendance are rooted in the technologies of reproduction and are part of the same history but they are pulling in different directions.

In the context of a first issue of The International Journal of Screendance, and hoping to encourage dialogues between screendance and other art practices, I will revisit the discussion on originality versus appropriation, which has underpinned developments in various areas of contemporary fine art practice. I will look at different approaches to appropriation and review the kinds of authorship that have emerged in the process. This includes an investigation into the logic of the copy inherent in these practices, wherein I will consider both the use of technologies of reproduction and the use of repetition within the work. In addition I will look at Appropriation Art through a choreographic lens and consider what screendance practices may be able to contribute to the debates on authorship.

For the purpose of my argument I will situate screendance in opposition to appropriation practices, even though that is problematic when you think about music videos (for example). They could be considered as a form of screendance in their emphasis

These works thrive on traditions of cultural commenting and recycling and freely combine, appropriate, remake, remix, spoof and parody. on choreographic sequences and moving dancing bodies, but they also appropriate and remix frequently from all kinds of cultural sources and media. The recent Video Phone by Beyonce (2009) and the remake by Lady GaGa (2010) come to mind, whereby both pop singers feature in each other's videos. Lady GaGa's remake inspired further spoof versions, performed, for example, by Him and Me TV (2010), all accessible on YouTube. These works thrive on traditions of cultural commenting and recycling and freely combine, appropriate, remake, remix, spoof and parody. Apart from music videos, though, much of screendance, and in particular the work that is shown in dedicated screendance festivals, is not explicitly engaged with the incorporation and appropriation of existing cultural material.

Appropriation as art practice rests on the idea of borrowing or copying rather than making something "new," that is, the incorporation of everyday objects and images into works of art or the copying of already existing works of art. Even though this may suggest a common methodology across different bodies of work, I do not want to argue for sameness between different appropriation practices, but rather explore the nuances and possibilities that distinguish different approaches. As Vera Dika argues in her book Recycled Culture in 
Contemporary Art and Film, we need to avoid generalities and simplifications in the discussions, as different appropriation practices cross different boundaries and explore various kinds of self-reflexivity (30).' To explore some of the operations at play, I will draw on different sources and points of view, mainly theorists Craig Owens and Margaret Iverson and anthropologist Verena Seremetakis, as well as my own experience in choreographic practices.

I will begin by discussing the video Snow (2003), a collaborative work by David Hinton and Rosemary Lee, which is above all a choreographic project and generally shown in the context of screendance, but which also draws on the tradition of Appropriation Art. The work sits therefore at a crossroads between screendance, visual arts and film practices. Following a discussion of Snow, I will broaden out to explore the work of artists who are associated with Appropriation Art and look at the aims and intentions of their different works. This will involve travelling backwards in time as the roots of these practices go back via the so called "Picture Generation" of the 1970s and 1980s to the use of the readymade at the beginning of the twentieth century. However, rather than drawing a map of Appropriation Art as such, my focus is on the correlation between appropriation and choreographic endeavours and the relation between making copies and making unique works of art.

I am writing this paper with a sideways glance toward Walter Benjamin's often quoted essay, "The Work of Art in the Age of Mechanical Reproduction"from 1936, in which Benjamin argued that the notion of the original and unique work of art was outmoded and that the technologies of reproduction, photography and film would allow for a new concept of art.2 His writing and the debates that followed proved highly influential in underpinning appropriation as an art practice. It will not be possible to fully review his argumentation in this paper but some of the issues discussed here will raise questions with regards to Benjamin's differentiation between the notion of the original and the copy.

\section{Series, playfulness and hard-core criticality}

The work Snow (2003) remixes black and white archive footage, dating from the 1890s to the 1960s, into a series of urban snow scenes (Figure 1, pp 30-31). The work begins with individuals vigorously flapping their arms and tapping their feet in an attempt to generate warmth, proceeds by cutting between groups skating and dancing on ice or shuffling through the streets, and ends with barely recognisable dark silhouettes braving violent snowstorms. The work is described as a "rhythmic choreography of gesture and actions on the slippery sidewalks and slopes of a bygone era" (Hinton and Lee, online). ${ }^{3}$

Snow brings a distant past into play with the present. Fragments of subjective histories and insignificant moments of the past are seen and remembered, perhaps for the first time. As a collection of out-takes huddled together on the screen, they have gathered sufficient mass to be noticed, attracting attention to what may have been lost otherwise. The grainy image quality of the archive footage further amplifies a sense of fragility in comparison to the video technology with which the work is screened. In a paper entitled "Resistance to Replication," given in the context of a debate on replicas at Tate Modern in London, Margaret Iversen discusses the effect of the presence of historical technologies in contemporary work: ". . just-obsolete technologies seem to condense both a promise for the future and a melancholic acknowledgement of the fading of those hopes. As 'found objects' they weave together past and future, memory and anticipation, and create a fabric of associations." ${ }^{\prime 4}$ 
Iverson highlights the changing status of the technologies of reproduction which, over time, have come to play very different roles. An example for the incorporation of obsolete sound technologies is Graeme Miller and John Smith's video, Lost Sound (1998-2001), which retrieves the sound of audiotape found on the streets of London and combines it with video images of the places where the tape was found. The work seeks out and replays, as if for the last time, a technology that encapsulates a whole era of sound making, constituting a remembrance as well as signalling its obsoleteness.

A similar dynamic plays out in Hinton's Snow, whereby outmoded film and contemporary video technologies are combined to invite a comparison between early amateur film footage and the contemporary equivalent. Whilst allowing for a nostalgic delight in archival footage, the work invites a reflection on ideas of technological progress that would have circulated at the time of early filmmaking.

In addition to this play on the material level in Snow, there are significant operations at work in the editing through the composition of a series of similar movement material. In this process the "historical" is detached from its original context, losing a sense of circumstance or narrative, and is embedded instead within a new structure, an accumulation built on formal qualities such as similar rhythm and corresponding shapes. This sort of operation is typical for work that appropriates existing material. It causes a shift from meaning that is located within the image to meaning that is created by the new series and the new context.

Exploring these compositional methods in works of art in the 1970s and 1980s, Craig Owens argues that the appropriation of found images is a Duchampian strategy dating back to the readymade, and also that it signals "a shift in elocutionary mode, from history to discourse" (75). ${ }^{5}$ The Duchampian ploy of taking an existing industrial object such as a bottle rack (Bottle Rack, 1914) and presenting it as art in an art context suffered a paradoxical fate: at first it confronted the traditional notion of an original art object and displaced the artists as the maker of the work. After the initial shock the readymade was, however, aestheticized very quickly by a homogenizing dynamic in the art market and reabsorbed into the exhibition space. Nevertheless, it could be argued that the readymade permanently destabilized the process of art making, shifting the attention away from the object to the cultural dynamics within which it was made, always and again highlighting an institutional context and its homogenizing mechanisms.

According to Owens this also caused a shift "from history to discourse," that is, a change from third-person narrative to direct address (75). Meaning as a certainty was replaced by a fluid and almost arbitrary process of an encounter between the art object and the viewer. Owens references this history in the context of appropriation practices of the 1970s because its practitioners began to systematically strip images and objects of their authority as carriers of meaning and articulated instead the processes through which meaning is assigned within a particular cultural context. Examples of this sort of practice include Sherrie Levine's appropriation of the work of other artists, as well as Dara Birnbaum's appropriation of TV material, both of which will be discussed further on.

Snow sits within this history and adds a chorographic perspective, bringing together archival film scenes from unrelated sources and appropriating them for its own choreographic purposes. The absence of narrative and original context creates a void that can only be filled by the viewer. As a formal sequence of fleeting moments, Snow invites the viewer to reflect on what we call "history"; as a choreographic endeavour, the work questions the 

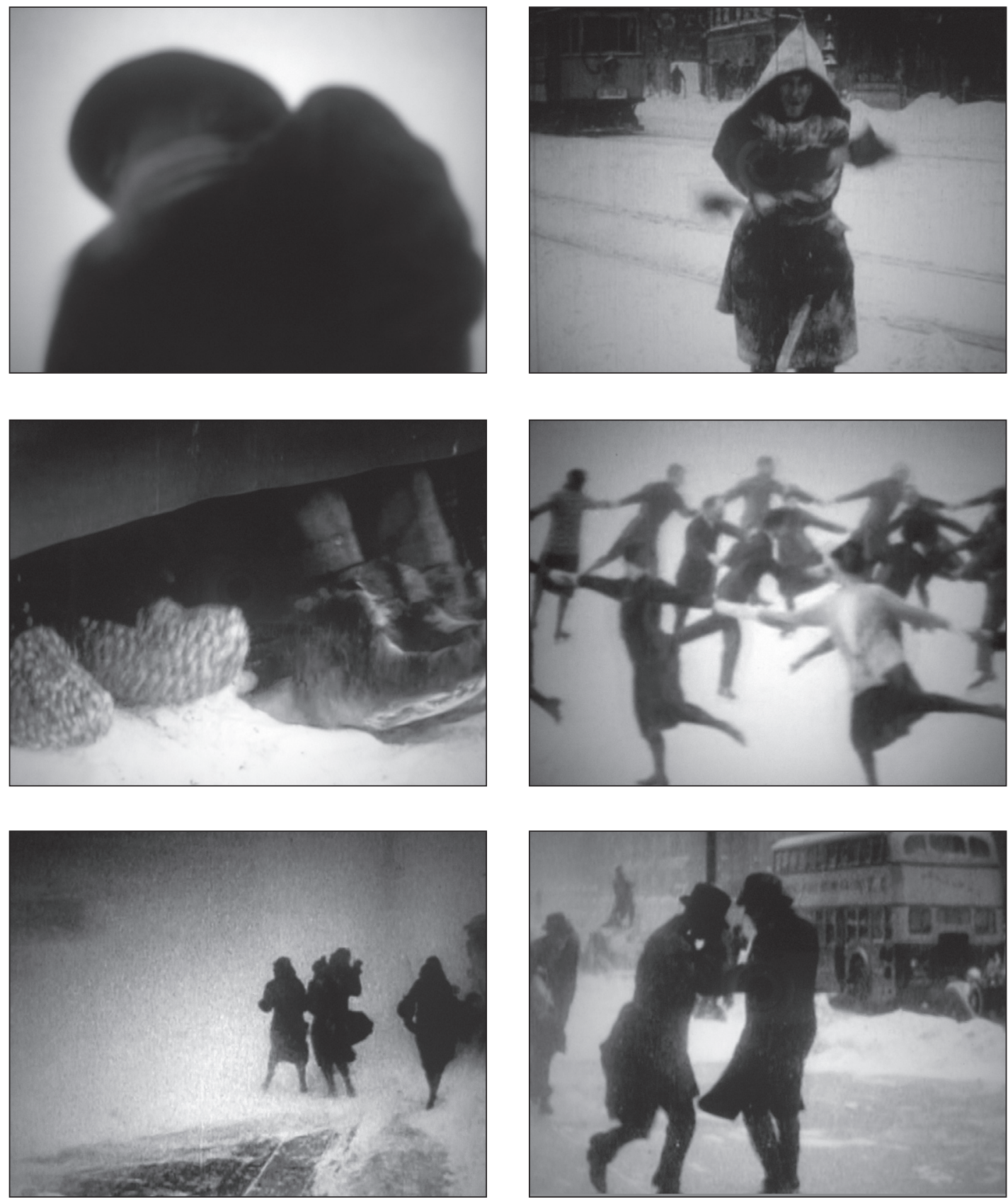

Figure 1: Snow (Dir. David Hinton and Rosemary Lee, 2003) 

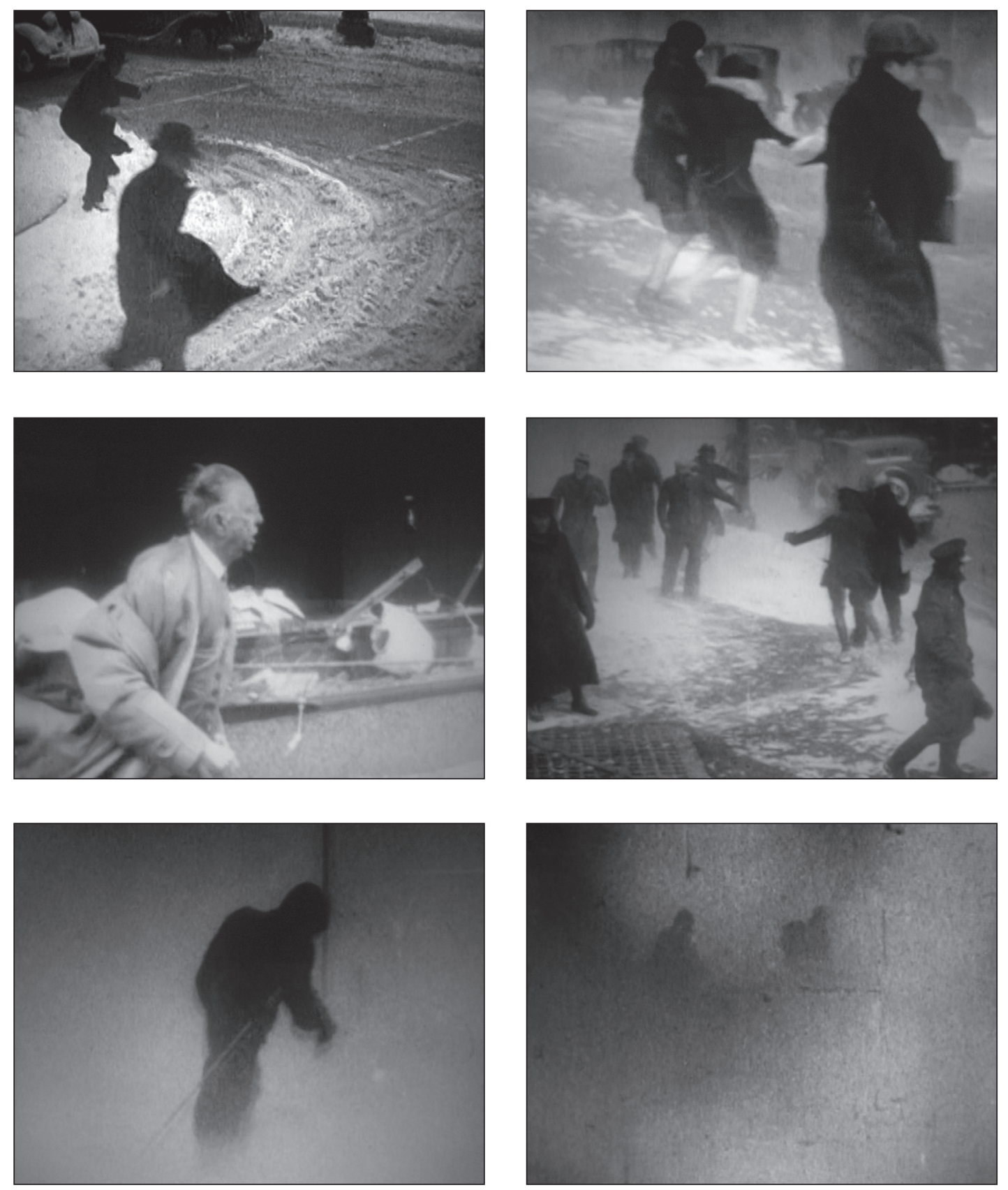
notion of the choreographic, as all the material was already in existence and no movement needed to be "written." The artist's "work" then consisted mainly in composing, in a sense, a response to what was already there, a process that is significantly different to the kind of authorship involved in making new material. In a work such as Snow, the author/maker/ choreographer does not claim a traditional form of ownership of the material and is more a disinterested kind of author figure.

The foundations for the model of the artist as disinterested figure had been laid by Duchamp through the readymade, as discussed above. In the late 1960s it was developed further by Roland Barthes in the essay The Death of the Author, in which Barthes argued strongly against the idea that an author could be the origin of a work of art and suggested that it was the work that was making the author. Barthes' essay was an invitation to re-invent authorship as a different kind of writing or making and emphasized the complexity of the process of making. In an essay entitled "From Work to Frame, or, Is There Life After'The Death of the Author'?" Craig Owens reviewed different kinds of authorship that subsequently emerged and that have tended to undermine the more traditional notions of authorship. ${ }^{6}$ | will not be able to expand here on the different threads in Owens' essay, but I would like to appropriate the title for my reflections of authorship in screendance. If I were to equate the author with the choreographer, I would call for the death of the choreographer, but I would like to try a different strategy in order to expand the notion of the choreographic and ask: "from work to frame, or, is there life after the death of the dancer?"

The point of a declaration of the death of the dancer is not to call for work in which there are no dancers - of which there are numerous examples-but rather to reflect on what it is that dancers represent within work and what role they are fulfilling with regards to authorship and the question of originality. Moving dancing bodies allow for the possibility of making "new" material and for a concept of the choreographer as the creator of the work, akin to traditional notions of authorship. This attempt to make original work is reinforced by the fact that individual bodies contribute a certain unpredictability on which the choreographer can draw to secure a uniqueness of the work. From this perspective, screen-based work without dancers would require the makers to relinquish some of the traditional claims to originality that are often inherent in choreographic project and located in the presence of moving bodies. In order to explore what authorship might look like without dancers, I will examine the work of a couple of contemporary appropriation artists, one with a playful and the other with a more serious approach.

Artist Christian Marclay works across visual art and sound art, taking artistic strategies from one field and applying them to the other. In some of his installations classic cinematic scenes and their sound effects are accumulated to expose the narrative conventions of film. In Quartet (2002), for example, cinematic moments such as telephones ringing and glass shattering are screened side by side across four large screens to create a hilarious comic-tragic soundscape. In Crossfire (2007), gun scenes from Westerns are edited into rhythmic series of increasing intensity. Shots of men in boots and cowboy hats facing the camera, reaching for their guns, pulling guns, pointing guns and finally shooting are edited into tight sequences with four variations of the same material projected simultaneously on four walls. Through the combination and pace of images and sound, the work bombards the viewer with cinematic tension from all sides. Crossfire could be described as a choreographic study of the cowboy, structuring the material in terms of movement and sound 
qualities, rhythm and framing, amplifying patterns and qualities of gestures. The work mocks cinematic representation and exposes a glorified emblem of masculinity.

Both Quartet and Crossfire seem quite close to their cinematic counterparts and very much the equivalent of cinematic spectacle within an art gallery. There is a strong sense of pleasure in looking and in the conventionality of the appropriated material. No matter how fragmented the material may be, the works acknowledge the importance of the little moments that flesh out the cinematic narrative-such as the ring of an old telephonewhich suggests that the artist is just as keen to fulfil to our desire for immersive experience as he is intent on introducing a critical distance.

Marclay fully embraces appropriation and exploits the processes across different media, working with film clips, strips of tape, record covers or old vinyl records. In The Sounds of Christmas (1999 and ongoing)he also invites other artists to make work with one of his collections, a large set of Christmas records, which travels from county to country and which he offers to local DJs and sound artists at Christmas time.

Marclay's work plays with repetition both on the level of content and technique, and he seldom "invents" material. His signature as an artist is to collect and copy and to create playful compositions with what he finds. In his discussion of Appropriation Art, Craig Owen argues that in this kind of operation fragments are piled up endlessly and "without any strict idea of a goal," a proposition that is drawn from Walter Benjamin's exploration of accumulation as literary process (Benjamin qtd. in Owens 43). ${ }^{7}$ The notion that there might not be a strict idea of a goal in the work highlights a disinterested kind of authorship, whereby the author lays no claim to making or breaking meaning. Instead of working with a sense of an origin and a destination, the artist builds on a process of replication inherent in contemporary culture and mass media and replicates this even further. By extension, the work crosses with ease between different media and traditions; thus a discussion on whether or not this work draws on choreographic sensibilities is of little consequence. By working with a process of replication the author does not need to secure any originality and can allow the work to unfold its meaning in relation to the cultural context from which it is appropriated. In this sense one could argue there is "no strict idea of a goal."

Marclay's broad, open framework can be seen as a response to the work of the 1970s and 1980s, when media artists demonstrated a more hard-core approach to appropriation, dealing explicitly with issues regarding gender, identity politics and capitalist ideologies. German artist Klaus vom Bruch made a series of works in the mid-80s which address the representation of self and identity. In Der Westen lebt (1984), vom Bruch uses rapid-fire video switching to juxtapose two very different scenes. One image shows the thrusting pistons of an oncoming train, the other a man and a woman kissing in a way that is at once erotic and violent, playful and disturbing. The high-speed editing creates a confused visual composite, with the effect that meanings bleed from one image into the other, juxtaposing the mechanical and the human as well as approximating the two. The sound of the train is edited into a hard, staccato rhythm and maintains the same tension throughout the work. Similar to Marclay's work, the composition builds on selected movement and sound qualities, but develops a more aggressive composition with a constant, staccato push and stop animation. The work comes across as a strong critique of a Western figuration of desire because of the single minded editing which pushes the male into the position of aggressive perpetrator and the female into a role as sexual object. 
In another of Klaus vom Bruch's works, Goblin's Chants (1986), a high contrast image shows a white male torso hovering in the middle of a black screen breathing rhythmically while a rotating tubular object is faded in and out over the chest. The movement on screen is accompanied by an Ethiopian call and response chant. Compared to the violence of Der Westen lebt, this video is seductive and hypnotic. The combination of elements is unsettling, however, and gives the impression of a strange, inexplicable ritual. How does an individual male torso relate to an anonymous technical structure and how does this pairing on a video screen relate to an African chant?

The uncertainty is the effect of a construct, whereby one fragment or layer is read through and against another layer. Appropriated for this work, each element clashes with the others and disparate cultural assets are collapsed into one frame. Owens argues that artists were "laying claim to the cultural significant and posing as interpreters," playing on the traditional role of creators of meaning but providing none of it" (54-55). ${ }^{8}$ Indeed, Klaus vom Bruch is not interested in making meaning but in making a critique of discursive conventions in popular media, advertising and television. Some material is taken straight from the media, such as the image of the train pistons or the Ethiopian chant; other material is made "in the style of," such as the scene of the man and woman kissing. Either way, vom Bruch uses an existing reservoir of images and gestures to expose them as constructs of a wider commodity culture. As a choreographic enterprise, the work copies from a limited cultural repertoire and highlights the limitations by staying within its boundaries.

Compared to Marclay's work this approach is minimalist and does not indulge the audience. A sense of duration and persistent repetition challenges the viewer and gives little opportunity for entertainment or visual pleasure, setting the work apart from the commodity culture that it is trying to critique. Considering the adherence to the principles of appropriation in this work, one might expect that there is not much of a sense of authorship, but that is not so. The author is palpable as a strict master of ceremony, in which all decoration has been removed and only the bare essentials remain. In appropriating a cultural repertoire, vom Bruch becomes the choreographer-director of this repertoire, re-staging well-known clichés and exposing them in the process.

Both Marclay and vom Bruch have an approach that is relatively disinterested, using and re-using existing cultural clichés, commodities and icons to make their point. On the other hand, and perhaps despite the exploration of already existing material, there is also a personal dimension to their work, and the artists seem to be quite at ease with this ambivalence. Their approach testifies to a certain criticality towards authorship but does not relinquish originality altogether. The work rather indicates an expanded notion of originality. I will proceed by discussing the work of two American appropriation artists from the so-called Picture Generation to further explore this point.

\section{The Picture Generation}

Artist Sherrie Levine is often called "the" appropriation artist. However, not uncommon for women artists of her generation, Levine is not keen to be drawn into the school of appropriation and even less to figure as its representative. She rather associates herself with the feminist discourses of the 1970s and their debates on notions of originality. In an interview 
for Arts Magazine in 1985, Levine was asked to comment on what originality meant to her. She responded:

It's not that I don't think that the word originality means anything or has no meaning. I just think it's gotten a very narrow meaning lately. What I think about in terms of my work is broadening the definitions of the word 'original.' I think of originality as a trope. There is no such thing as an ahistorical activity (I mean history in terms of one's personal history, too). ${ }^{9}$

By bringing in the personal dimension Levine references a feminist discourse that argued against universal classifications and narratives, and for a foregrounding of the local and the personal. The discourse supported a notion of subjectivity but problematized the concept of originality, arguing that there was no such thing as an artist who was not already embedded in a particular culture, economy and history. Levine does not, however, propose to abandon the concept of originality as has been suggested elsewhere, but argues that it needs to be reviewed and broadened.

Levine was part of a group of artists who came to prominence in 1977 through an exhibition at the alternative Artists Space in New York entitled "Pictures," curated by Douglas Crimp. Like Levine, artists such as Robert Longo and Jack Goldstein worked predominantly with film and photography, demonstrating a new fluidity between practices, genres and media and drawing on mass culture, television and advertising as much as the history of painting and minimalist sculpture for their own work. On the occasion of a review of the work of the Picture Generation at a show at the Metropolitan Museum of Art in 2009, curator Douglas Eklund reflects on the effects of the political climate and the mass culture on the production of art in the 1970s and 1980s. He describes it as a time of disillusionment and failed utopian promises of political and social transformations. Artists, he writes, were working "at the intersection of personal and collective memory, rummaging through the throwaway products of their youth ... in search of moments that both never existed yet were indelibly stamped in the mind." ${ }^{\prime 0}$ The statement foregrounds the fact that artists were deeply implicated as consumers of a proliferating visual culture whilst trying to find a critical voice from within. Eklund describes this culture of movies, television, popular music and magazines as a "sort of fifth element or a prevailing kind of weather," and the artists as scavengers of this image world (ibid.) As Margaret Iversen points out in her review of this body of work: "To appropriate, copy, replicate became the new, inverted, 'anti-aesthetic' values" (Iverson, online). This "anti-aesthetic"was above all a specific rejection of a Modernist tradition which advocated a separation between different media and genres and which celebrated the artist as creative genius. The new generation of artists inverted this aesthetic by replacing a process of creating with a process of copying and by replacing the separation between genres with a deliberate blurring of categories.

Levine's own take on appropriation constituted perhaps the most radical challenge to the notions of originality and authorship. Since 1977 Levine has copied and re-presented the works of other artists, showing for example photographs of natural subjects that had been taken by photographer Andreas Feininger (Owens, 75). In re-photographing and presenting the work of another artist the images fall somewhere between being "his" and "hers" and are neither the original picture nor simply a copy. Instead the works raise doubts as to the nature of authorship and the status of images themselves. In the interview for Arts Magazine, she explains: 
When I started doing this work, I wanted to make a picture which contradicted itself. I wanted to put a picture on top of a picture so that there are times when both pictures disappear and other times when they're both manifest; that vibration is basically what the work's about for me - that space in the middle where there's no picture. (Owens, 75)

As Levine points out, this work is highly contradictory and reflects a complex artistic process, calling into question the whole of the relation between artist and work. In this work we cannot locate the author but neither can we clearly identify the image inside the frame. The deployment of photography here is symptomatic in that a photograph is never an authentic, original object in the first place. Photography and film are always images of something and to ask for an authentic print makes no sense, as Benjamin noted in 1936 (218). Meanwhile a predominantly visual culture had lost interest in the notion of the original and Levine's re-produced pictures refuse to act as transmitter of cultural signification. According to Craig Owens such images "both solicit and frustrate our desire that the image be directly transparent to its signification. As a result, they appear strangely incomplete; fragments or runes which must be deciphered" (55). Instead of producing authoritative works of art, Levine undermines the reification of art objects by making work that is to some extent incomplete and which is neither her work nor that of the artist she is copying. In addition, Levine has only ever taken images of male artists to address a canon that has tended to privilege the male as artist, curator and recipient. Levine said: "A lot of what my work has been about since the beginning has been realizing the difficulties of situating myself in the art world as a woman, because the art world is so much an arena for the celebration of male desire" (Siegel, online). Her work plays a complex game of addressing gender politics, authority and the figuration of desire as male. In appropriating this "other" she has opened up a space in which there is no defined author and no classifiable work but a mode of operation all the same.

Levine's extreme approach to appropriation demonstrates a strong interest in questions of originality and authorship. It is interesting in this respect that after working through photographic reproduction she began to physically draw the work of male artists such as de Kooning, Piet Mondrian and Yves Klein, thereby re-introducing the hand and by extension her individual presence into the work. Through this introduction of physical trace the work became a curious hybrid, being both appropriated as well as original, pushing the boundaries of Appropriation Art and challenging the positioning of her as (appropriation) artist at the same time.

Levine's appropriation of other artist's work correlates to some extent with the work of Dara Birnbaum, who appropriates footage from television to create video loops, which replicate the clichés of television. An early work is Technology/Transformation: Wonder Woman (1978-79), an appropriation of sections of a popular TV series from the 1970s entitled '"Wonder Woman," and in which Birnbaum endlessly repeats characteristic moments of the main character such as her transformation from real woman to super woman.

The extracted clips are combined using a stuttering progression and persistent repetition to create a minimalist choreography consisting of running, spinning and saving a man's life. Through the repetition the images shift from being screen magic to pathetic looking effects, deflating the icon and turning Wonder Woman, almost literally, into a wind-up doll. In the process the original television series is revealed as a rigid choreography with a prescribed series of movements, limiting the main character to very tight parameters. 
Birnbaum's critique, however, was not as confrontational or as "hard core" as is sometimes assumed. In an interview conducted in the context of the "Talking Back to the Media" festival in the Netherlands in 1985, Dara Birnbaum speaks about her intentions in this body of work. Asked if her early work was about "talking back to the media," Birnbaum responds: "No, I think that never was the main subject. I wanted to talk about a form of representation and its issuance ... Rather than pointing the finger, rather than Talking Back at something, it is more important to Talk With" (Velthoven).. "Instead of an antagonistic artistic position her comments suggest something close and even intimately connected to the media. In isolating and re-editing the material the artist extends an invitation to the viewer to also look closely and to consider the image itself as well as any cultural subtexts to which it may refer.

In the same interview, Birnbaum talks about an acceleration in visual culture and television that is speeding up to the point of collapse. She says that to resist this development she has had to go slower, to make slower and slower tapes. Birnbaum describes how she was inspired by seeing Japanese prints in the Van Gogh museum in Amsterdam, which appeared to her like a "stop in TV time." Her comment suggests that she was searching for a different kind of visual experience than the one offered by television. Perhaps Birnbaum's work has always been an attempt to stop or slow down the pace of broadcast media, which tend to overwhelm the viewer with a continuous barrage of visual and audio material of any kind. The extraction and repetition of small snippets from television counteract this flow and the dramatic content of the material fades away with each repetition. Exhibited as loops, the work creates a reflexive interval, as if a stilling is the act that is performed here.

Anthropologist Nadia Seremetakis has developed a critique of dominant cultural modes from an anthropological point of view, commenting on a construed evenness and artificial sameness of cultural codes. Individual experience, Seremetakis argues, is, by contrast, uneven, regional, non-synchronous. She claims that representational modes need to be interrupted to "render the imperceptible perceptible" and to allow for different kinds of individual experience (12). ${ }^{12}$ Seremetakis proposes the concept of the "still act" as an interruption which would suspend at least momentarily a homogenizing culture that erases individual experience rather than articulating it (23). These still acts would not just be passive moments but an active and deliberate process, a paradoxical intervention that asserts a possibility of reflection and an artistic agency. This concept could be applied to Birnbaum's Wonder Woman, which plays with and against the language and rhythm of broadcast media to deconstruct its narratives and conventions.

"Readymade for the 20th century" was the title Dara Birnbaum gave to her video work from the 1970s in reference to artist Marcel Duchamp and in acknowledgement of a history that pushed aside the unique art object and replaced the artist-genius with a more detached author figure. The appropriationists discussed in this paper all seem to embrace this history and work with the copy as compositional strategy. On the other hand though, Birnbaum, Levine, Marclay and vom Bruch all pursue an art practice that is not entirely disinterested. A clear sense of signature emerges with each of the projects, indicating that some kind of originality has survived even in extreme forms of appropriation.

The authorship also seems multifaceted, with artists borrowing an infinite number of strategies to realize their projects, and the works described would perfectly make sense if they were screened in the context of screendance. Choreographic processes are at play even 
if they are not generally described as such; a work such as Snow demonstrates that there are no real boundaries between the two bodies of work, Appropriation Art and screendance. However, in spite of a proximity and resemblance in the work the artists are not at present exhibited in the same context, as if either party had sworn an allegiance, due to which they cannot cross an invisible line. The discourse on authorship as discussed above will account for some of the separation, but Benjamin's influential essay from 1936 must also play a part in this. I will review a few aspects of his essay to further explore the roots of screen-based practices and to outline the kind of authorship that screendance appears to be pursuing.

\section{Ebb and flow between the real and the copy}

First of all, it might be useful to recall that the strategy of the readymade, which was once radical and revolutionary, has over time become an accepted aspect of art making and that this development is due in part to the changing status of the technology of reproduction. Iverson argues that "these confident technologies that once participated in the shock of modernity now open themselves to reverie. The commodity fetish and advanced technologies of reproduction, now cast aside by the march of progress, become pensive."13 Iverson reiterates the fact that the environment around the art object has changed considerably in terms of familiarity and availability of technologies, and that this has affected the status of and response to reproduction in art. The shock of the readymade has turned into an easy acceptance of the technologies of reproduction, which in turn could explain why a seminal essay such as Walter Benjamin's "The Work of Art in the Age of Mechanical Reproduction" slowly fades into history. In this essay Benjamin claimed that the technologies of reproduction shattered the traditional authority of the art object which had been built on being unique and original, and that the arts needed to embrace the new technologies as a more adequate form of art practice for the twentieth century. He argued that this new kind of art was "lacking in one element: its presence in time and space, its unique existence at the place where it happens to be" (214). This "lack" and his text in general is usually read as a wholehearted endorsement of the new technologies and as a condemnation of the traditional value of presence of the unique work of art, or "aura" as he called it. Accordingly Benjamin's essay underpinned a categorical distinction between the traditional unique object and reproduction in art. In view of contemporary screen-based practices and with regards to audience experience this distinction is, however, difficult to sustain.

Screen-based work appears to facilitate a sense of space and time not unlike the encounter in real space, in particular when individual bodies are figured in relation to other bodies or in relation to particular sites. Hybrids like screendance are able to combine different practices and strategies, capitalizing on both the technologies of reproduction and the singularity of performance. The screen enables a paradoxical experience, in that it is always only an image but allows audiences an experience that compares to seeing live work or real objects. In a discussion on cinema as modern magic, film historian Rachel Moore explores this fundamental paradox of film and points out that the absolute separation from real space is exactly that which allows film to be perceived as real (86). ${ }^{14}$ Benjamin wrote that "the presence of the original is the prerequisite to the concept of authenticity" referring to the authenticity of the art object, but film allows for an experience of presence despite the fact that it is always only a reproduction. ${ }^{15}$ 
Presence must therefore be reconceived not as a requirement of the "object" but as an aspect of the experience offered by the work. Particularly in the case of screen-based work, presence may not at all depreciate with reproduction, as Benjamin suggested, but continue to exert the same presence across an infinite number of copies. Benjamin further proposed that "the authenticity of a thing is the essence of all that is transmissible from its beginning, ranging from its substantive duration to its testimony to the history which it has experienced" (215). Benjamin describes what he understands as the aura of a work of art, a combination of the particular of place and time, the unique history and the evidence of this history in the art object. One could argue, however, that this can be transferred from the art object to the object of representation, i.e. screen-bodies, through which a substantive duration and a history can be located within the work and experienced by the viewer. Screen-based work is therefore anchored through the detail or the screen body in space and in time and allows for an experience of presence and uniqueness on the part of the viewer in spite of the nature of the work as mechanical reproduction.

In the latter part of his essay Benjamin elaborated with excitement on the deepening of perception which had become possible through photography and film and his own writing appears to supports my argument. Benjamin writes:

By close-ups of the things around us, by focussing on hidden details of familiar objects, by exploring commonplace milieus under the ingenious guidance of the camera, the film, on the one hand, extends our comprehension of the necessities which rule our lives; on the other it manages to assure us of an immense and unexpected field of action ... The enlargement of a snapshot does not simply render more precise what in any case was visible, though unclear: it reveals entirely new structural formations of the subject. (229-30)

In this passage Benjamin explores the possibility of close-up and a revelation of detail without, however, considering that they could facilitate a sense of presence and uniqueness. He does not make the connection between the "auratic" experience that a traditional painting would have offered and the new kind of encounter that only a camera makes possible. And while he did acknowledge that the tasks of art forms, which are formulated within a body of work, are often only realized much later and within a new art form, he did not apply this to the presence of a painting and the presence that is invoked through the medium of photography or film. "I see this unreal thing exactly" is a quote from Epstein, which Rachel Moore brings into the debate to highlight the kind of experience that the new art forms facilitate. She argues that it is precisely this gap between the real and the representation which fuels the desire of the spectator (86).

We have therefore a history in which, initially, the technologies of reproduction displaced the unique art object in order to replace it with the logic of the copy prevalent in mass culture, and where, later on, the same technologies re-affirm the possibility of a continuity of the traditional values of presence and originality. In difference to most readings of Benjamin's essay, Iversen proposes that a wholehearted endorsement of a liquidation of a tradition may in any case be a misreading of Benjamin and that he did not actually dismiss our desire for the unique, or what he calls the auratic experience. This suggests a far more ambivalent situation, and Iverson proposes that the current "post-modern condition" might consist precisely of this ambivalence between a celebration of the copy on one hand and a desire for an auratic mode of experience on the other. Describing the same kind of ambivalence, Rachel Moore writes: "The pleasure of the spectator resides not in the pure fantasy 
of illusion but in providing a screen upon which to exercise the 'ebb and flow' between the real and the copy" (87). Moore proposes that the contemporary spectator seeks an art form in which the real and the reproduction coexist to allow for a flow between different modes of engagement.

It might be useful to position screendance within this paradox, as an art form that is rooted in technological reproduction and whose makers can both pursue this logic and seek to explore the unique and irreplaceable. Without an opposition between a notion of originality and the copy, a strict notion of disinterestedness on the part of the artist also appears redundant, and a more fluid concept of authorship seems more appropriate. I agree with Iverson in that there is "a need to complicate the tradition of disinterestedness and the displacement or effacement of subjectivity implied by the reiteration of the readymade."16 A complication would makes sense with regards to the relation between the copy and the unique presence within screendance practices and invite further reflection on the role of the body on screen as well as on spectatorship. As always bodies complicate the issues as they blur the boundaries between the author and the product, contributing as individuals whilst also being part of the "work." In this sense screendance may be able to offer exactly the kind of complication that Iverson calls for in order to advance debates on appropriation and authorship.

\section{Notes}

1. Dika, Vera. Recycled Culture in Contemporary Art and Film. Cambridge: Cambridge University Press 2003. Print.

2. Benjamin, Walter. "The Work of Art in the Age of Mechanical Reproduction." Illuminations. London: Pimlico, 1999. 211-244. Print.

3. Hinton, David and Rosemary Lee. Snow. London: Arts Council/ BBC 2003. Web. 25 March 2010. <http://empac.rpi.edu/events/2006/dancemovies3.html>.

4. Iversen, Margaret. "Resistance to Replication." Tate Papers Autumn 07, Issue 8. London: Tate Modern. Web. 25 March 2010.

5. Owens, Craig. "The Allegorical Impulse: Towards a Theory of Postmodernism, Part 2." Beyond Recognition, Representation, Power, and Culture. Berkeley: University of California Press. 1992. Print.

6. See Owens, Craig. Beyond Recognition, Representation, Power, and Culture. Berkeley: University of California Press, 1992. 122-139. Print.

7. Benjamin, Walter. "The Origin of German Tragic Drama," quoted in Owens 43.

8. Owens, Craig. "The Allegorical Impulse: Towards a Theory of Postmodernism." Beyond Recognition, representation, Power, and Culture. Berkeley, Los Angeles: University of California Press, 1992. Print.

9. Siegel, Jeanne. "After Sherrie Levine: An Interview with Sherrie Levine." ARTS Magazine, (Summer 1985). Web. 23 March 2010.

10. Eklund, Douglas. "The Picture Generation." New York: The Metropolitan Museum of Art, 2009. Web. 25 March 2010.

11. Velthoven, Willem. "Birnbaum interviewed by Willem Velthoven." Talking Back to the Media Festival. Mediamatic Magazine 1.1. Web. 7 March 2010.

12. Seremetakis, Nadia C. "Memory of the senses, Part I: Marks of the Transitory." Ed. N. Seremetakis. The Sense Still: Perception and memory as material culture in modernity. Chicago: University of Chicago Press, 1994. Print.

13. Iversen, Margaret. "Readymade, Found Object, Photograph." Art Journal 63.2 (Summer 2004): 57. Web. 7 March 2010.

14. Moore, Rachel O. Savage Theory, Cinema as Modern Magic. Durham: Duke University Press 2000. Print.

15. Benjamin, "Work of Art," 214.

16. Ibid., online. 